\title{
PARALLEL COMPUTATION OF LARGE LEAST SQUARES PROBLEMS INVOLVING KRONECKER PRODUCTS ON THE CONNECTION MACHINE 5
}

\author{
Charles T. Fulton and Limin $W_{\mathrm{u}}$ \\ Department of Applicd Mathesnatics \\ Florida listijtute of Technology \\ Melbournc, Florida 32901

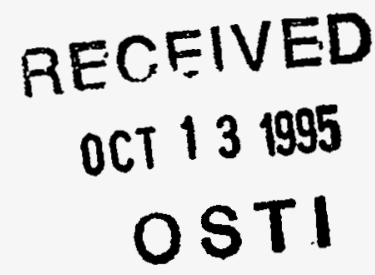

July 1995

\begin{abstract}
We present in this paper some timing results for a Dalis Prasulla: Version of a Kronecker Product. J,ciast Squares ('ode on 1.lie: Conneclion Machine 5
\end{abstract}

This ruscarch was supported undur Contract No. 1030N0014-8ll with Los Alamos Naliunal laboratory.

\section{Introduction}

In this papar we deseribe the implementation of un algorit/m for coinpuling the solution of the Kro vic:kesp Product least squnres problem

$$
(A \otimes B) x=t
$$

or, equivalently,

$$
\left(B \cdot X \cdot A^{T}\right)=T
$$

with $x=\operatorname{vec}(X)$, and $t=\operatorname{vcc}(')$, in the full $-\operatorname{rank}$ case in Data Parallel CMFortsan on the Connection Machine 5. Mnro $A$ and $B$ are renl malrices of dimensious $m \times p, m>p$, and $n \times q, n>q$, with $\operatorname{rank}(\Lambda)$ $=p$ and $\operatorname{rank}(B)=q$. Also, $X$ is $q \times p_{1} T$ is $n \times m$, and $\operatorname{vec}(X)$ denoties the vector consisting of the stacked columns of the malrix $X$. 'I'he algorithm is cssculially that given for the i860 Intel in [2], although a few modifications wcre required in the porting to CMliortran, and in thr Hduplation to the CMSST. (Comection Ma ehine Scientific Softwarc l,ilbrary) library routines.

We recall bricily the algorithm. Jeel tha malrices $A$ and $B$ be decompensed by QR factorizations wills column pivoting so that.

$$
A \cdot P_{A}=Q_{A} \cdot\left\{\begin{array}{l}
R_{A} \\
0
\end{array}\right\}
$$

and

$$
B \cdot P_{B}=Q_{s} \cdot\left\{\begin{array}{l}
R_{B} \\
0
\end{array}\right\}
$$

where $Q_{A}$ and $Q_{B}$ arc $m \times m$ and $n \times n$ real orllogonsal matrices respectivcly, $R_{A}$ and $R_{A}$ are $p \times p$ and $q \times q$ real upper triangular tustrices respectively, and $P_{A}$ and $P_{B}$ are $p \times p$ and $y \times q$ permutation malrices respectively.

Letling

$$
Q_{A}=\left(Q_{A 1}, Q_{A 2}\right), \quad Q_{n}=\left(Q_{D_{1}}, Q_{B_{2}}\right)
$$

where $Q_{A 1}$ is the malrix of the first $p$ columns of $Q_{A}$ and $Q_{B\}}$ is the metrix of the first $y$ columns of $Q_{B}$, and putting

$$
Y=P_{B}^{T} \cdot X \cdot P_{A}
$$

thic leasl squares problem (2) may be writlen in the equivalent form

$$
\begin{gathered}
\left\{\begin{array}{rr}
R_{B} \cdot Y \cdot R_{A}^{T} & O^{(2)} \\
O^{(1)} & 0(3)
\end{array}\right\} \\
=\left\{\begin{array}{ll}
Q_{H 1}^{T} \cdot T \cdot Q_{A 1} & Q_{b 1}^{T} \cdot T \cdot Q_{A 2} \\
Q_{B 2}^{T} \cdot T \cdot Q_{A 1} & Q_{B 2}^{F} \cdot T \cdot Q_{A 2}
\end{array}\right\}
\end{gathered}
$$

DISTRIBUTION OF THIS DOCUNENT IS UNLIMITED 


\section{DISCLAIMER}

Portions of this document may be illegible in electronic image products. Images are produced from the best available original document. 
whore $U^{(1)}, O^{(2)}$, and $O^{(3)}$ are zero inalsices of order $n-q \times p, q \times m-p$, and $n-q \times m-p$ respectively. Ii. follows that the least squares solution of (8) or (2) is the exact. Helution of the nonsingular gystem

$$
R_{B} \cdot Y \cdot R_{A}^{T}=Q_{B 1}^{T} \cdot T \cdot Q_{A 1}
$$

or, equivalently,

$$
\left(R_{A} \otimes R_{B}\right) \operatorname{vec}(Y)=\operatorname{vec}\left(Q_{M 1}^{\top \cdot} \cdot \eta^{\prime} \cdot Q_{A 1}\right) .
$$

With

$$
H=Q_{B 1}^{T} \cdot T \cdot Q_{A 1}
$$

we have the two str.p) procedlure for computing $Y$ from II: Leet

$$
Z=R_{B} \cdot Y
$$

alsd wrile $\mathcal{Z} \cdot \Omega_{A}^{2 "}=H$ in transposed form us

$$
R_{A} \cdot Z^{T}=I I^{T} .
$$

The backsolves indicaled in equations (13) and (12) are perfertly parallel since thcy can be performed independently to generale the columns of $z^{T}, Y$ from the collumns of the 'right hand sides' $H^{\prime \prime}, 7$ respectively. The basic algorithm is therefore as follows:

Stop 1: Counpule the $Q R$ factorization of $A$.

Step 2: Computc the $Q I$ fuctorization of $B$.

Siep 3: Form the right. hand aide vectors for the hacksolvcs in equation (13) by computing litic matrix product

$$
H^{T}=Q_{A 1}^{T} \cdot T^{\gamma} \cdot Q_{B 1} .
$$

Slep 4: Perform the backsolves in equation (13) by distributing the columns of $I I^{T}$ 'equally' aeross the proccssors.

Step 5: Compule the transpose of $Z^{\prime \prime}$ to get the right hand side veclors $\%$ for equation (12).

Slep 6: Perform the backsolves in equation (12) by distributing the columne of $Z$ 'equally' across the proc.cesors.

Stop 7: Connpule the least squares solution in matrix form using eqquation (6), viz.

$$
X=I_{B} \cdot Y \cdot P_{A}^{T}
$$

Step 8: Finally, the residual is computed from (2) as the Frobenius norm of

$$
T-\left(B \cdot X \cdot A^{T}\right)
$$

\section{Implementation of Least Squares Al- gorithm in CMFortran}

The three main paradigms currently available for parallel programming on ligh Performance Complutcrs are (i) sliared-memory (ii) explicjt messagc-pussing and (iii) data parallal. On a given machine these. paradigms may exist either in hardwarc or soltwarc, or a combination. On the Connection Macline 5 the data parallel and message passing paradigms arc available, but the shared- mernory paradigm is not. The above deseribed algorithm was implemented un the Connertion Machine 5 using CMFortran in the (global) data parallel paradigm.

All steps of the algorithus wcre implemented using standard CMSST. (Connection Machine Scientifie. Software Library) routines from [3], except for the backsolves in alepy 4 and 0 , which were codsed explicitly in data parallel CMlortran. The reason for this is that in the CMSSL Library (see [3], Chap. 5) the gen-lu-factor and gcrt-lu-solve routines are orgunized as a coupled sel for performing Gaussian elimination, and one camsot make use of the backsolver without first performing the LU dccomposition, even for an upper triangular input malrix. At this writing we have been advised that 'l'hinking Marlines Corporation does not have plans to produce a stand-alone. backsolver for upper triangulas matrices in fulure releases of the CMSSI, Jibrary.

Each slep of the above: algorithm was timed soparntaly. Hlore we describe which CMSSL routines were used for these timings. lor steps 1 and 2 tho QlR-factorigations in (3) and (4) were computed using CMSSI, routine gen - qr - factor; the times te ported include the times to recover the $Q, R$ and $P$ matrices in full storage mode using the CMSSI. sontincs $g c n-q r-a p p l y-q, g c n-q r-g p t-r$, and $g \in n-q r-a p p l y-p$. For step 3 the right hand side matrix $H$ was computed using (11) and CMSSI, rontincs mulnul abd transposc. For step 5 the transpose of $Z^{T}$ was computed using CMSSl, routine transpose. For stcp 7 the solution matrix was compuled using (15) and the matmul und transpose routincs. llere the permutation matrices $I_{A}^{2}$ and $P_{B}$ were usc. in full storage mode. 'The reason for this inefficient computation using permutation matricess is that the CMSSI. T.jbrary rolutincs associated with the QR-facturization make no provision for direct recovery of the pivol vector associated with the column pivoting in the $Q$ R factorization of the input malrix. It seems that this is due to thr. fact that the $Q R$-[actorizations are performed on a block cyclic permulation of the input matrix, so that 
the pivol vector associaled will the inpul matrix jtsclf nover gets generated. P'or slep 8 the residual is compuled uying (16) and the Frobonius norm using CMSSL roulines matmul, transpose and sum.

The $A$ and $B$ matrices (and the right hand side matrix $T^{\prime}$ yielding known solution $X$ ) were generated

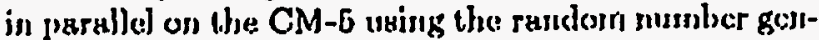
erator KNC; but. this preliminary step was not timed.

In the Data Parallel paradigm the smallest partition size which can be used on the CM5 at los Alaniog Nelional Laboralory is 32. Accordingly, with 1 VUs/node, a 32-node partition functions as a SIM.I) machine with 128 processsing elcrrsents all opcraling in parallcl.

\section{Backsolve Coding}

We describe here the mannor in which the backsolve coding for steps 4 and 6 was accomplisbed. Since the parallelism in the backsolving consists of doing equal numbers of backsolvcs on each processing elcuncril (number processing elenculs $=1^{*}$ NPHOCSS, where NPROCS is the number of processurs in the partition) we: Irnde use of a "serial" axis acroks the rows of the $H^{\prime \prime}$ and $Z$ malriccs and a "newg" axis ucross their columns. This luyout [orces all compo sleuls of each right hand sidc veclur to reside on a single $V U$, and takes care of the load halancing by plucing $N / N$ PROCS backsolves on each VU; the load balancing is therefore perfect when $N$ is divisible by NPROCS, while some processors will have one more backsolve to do when $N$ is not divisible by NPROCS. 'the upper triangular matrices $l_{A}$ and $R_{B}$ are, on the other hand, front end arrays stored as one-dimensiomal arrays with a "scrial" layoul directives. If $H$ is the matrix of right hand side vectors, and $Y$ is the matrix of soluliton vectors, then the CMForl.rnn code for the $N$ bncksolves of the upper triangular inalrix $R_{A}$ (or $R_{B}$ ) is нs follows:
Code Segment for Backsolves (sleps 1 \& 6):

\begin{tabular}{ll}
\hline CMIS & LAYOU'I' Y(:SLILAL,NEWS) \\
CMFS & LAYOUT H(:SFRIAI,:NFWS) \\
CMI'S & LAYOU'I'I'(:NLWS) \\
CMI'S & LAYOU' R(:SLIUAL)
\end{tabular}

Do $10 \mathrm{I}=\mathrm{N}, 1,1$

$$
\mathrm{Y}(1, \mathrm{i})=\mathrm{Il}(\mathrm{I}, \mathrm{i})
$$

$T(:)=0.0$

1) $\mathrm{K}=\mathrm{I}+1, \mathrm{~N}$

$T(:)=R(J B E G+K) * Y(K, ;)+T(:)$

ENDO

$Y(I,:)=(Y(I,:)-T(:)) / R(J B E G+1)$

C JIBI:G = index of 1-D array R. such that $C$ $R(J B L G+1)=(1,1)$-element of $R_{\mathcal{A}}$

10 Continue

\section{Timing Data}

Timing dals was collected only in the casc of square matricn:s $A$ and $B$ of ordet $N \times N(N=\pi h=$ $p=n=q$ ). For comparison with the actual timing dala we list in Table 1 the (serial) operation counts for each stcp of the algorithm.

Table 1: Operation Counts for $N \times N A$ and $B$ Malsices

\begin{tabular}{|c||c|c|c|c|}
\hline$N$ & 3st QR & 2nd QR & KHS & 1st BS \\
\hline$N$ & $(4 / 3) N^{2}$ & $(1 / 3) N^{3}$ & $4 N^{3}$ & $N^{3}$ \\
\hline transp & 2nd BS & Perm & Total & Res \\
\hline- & $N^{3}$ & $1 N^{3}$ & $(38 / 3) N^{3}$ & $4 N^{3}+N^{2}$ \\
\hline
\end{tabular}

In 'luble 2 we give the CM Busy times in scconcls for each step of the algorithm when the order $N$ of $A$ and $B$ is 1024 . This run was done on a 32 -node partition; conseyuently, 128 VUs ware employed, so the mumber of backsolves por VU doue in steps 4 ankd 6 was $1024 / 128=8$. For this mun the residual from the $1024 \times 1024$ matrix in (16) was

$$
\left\|r^{\prime}-\left(B \cdot X \cdot A^{2}\right)\right\|_{\boldsymbol{r}}=0.000518
$$


Table 2: CM Busy 'lime (in seconds) for $1024 \times 1021$ $A$ and $B$-Mutriccs

\begin{tabular}{|c||c|c|c|c|c|}
\hline NPROCS & 1st QLR & 2nd QR & RHS & 18t BS \\
\hline 32 & 12.742 & \multicolumn{2}{|c|}{12.793} & 3.959 & 10.838 \\
\hline transp & 2nd BS & Perm & Total & Res \\
\hline 0.099 & 10.839 & -3.826 & 55.196 & 3.940 \\
\hline
\end{tabular}

In Table 3 the megaflop rale for each stcp of the ulgorithrn is given using the data from T'ables 1 and 2.

Table 3: Megaflops/sec for $1021 \times 1024 A$ and $B-$ Matrices (1M - 1 Megallop/scec)

\begin{tabular}{|c||c|c|c|c|}
\hline NPROCS & 1st QR & 2nd QR & R.IIS & 3at I3S \\
\hline 32 & $112.30 \mathrm{M}$ & $113.81 \mathrm{M}$ & $1084.86 \mathrm{M}$ & $99.00 \mathrm{M}$ \\
\hline tranap & 2nd 13S & Ierm & 'lotal & Hes \\
\hline- & $99.06 \mathrm{M}$ & $1098.88 \mathrm{M}$ & $166.09 \mathrm{M}$ & - \\
\hline
\end{tabular}

'The effectivencss of the cxplicit backsolve coding in scction 3 can be seen by comparing the measured timo in Table 2 to the minimum thenretically feasible linne. Situce one slore operation requires 1.0 microseconds and one operalion count (mulliplication, addilion or division) requires 0.5 microseconds the total expecled theorelical lime for one backsolve of an $N \times$ $N$ malrix is

$$
1.0\left(N^{2} / 2+2.5 N\right)+0.5 N^{2}=N^{2}+2.5 N \text { micrusces }
$$

or 1.05 scconds when $N=1024$. Accordingly, by the load balancing innplemented in the backsolve coding, llice will be 8 backsolves done on each of $128 \mathrm{VUJ}_{B}$, so the expected minimum time on each VU is $8 * 1.05=$ 8.42 seronds. The measured CM Busy time of 10.84 seconds for cach of the two sets of backolves thus rcprescnts $128.7 \%$ of the theoretically expected minimum lime.

\section{Acknowledgements}

We thank Vance Faber for his support of this work. The firat. allthor acknowledges support from Contract No. 1030N0014-9H and the secend author acknowledges support from a graduate studont ri:seurch assistantship at Los Nlamos National Jaboralory. We thank several colleagues from the Computer lieseurch and Applications Division at I.ANT, particulurly lialph Brickner, Wayne Joubert, Olaf Lubcck, and Tom Mantcuffol for helpful discussions, and several consultants from 'l'hinking Machines Corporatiou, purticularly Pablo Tamayo, Daryl Grumav and Ilicliard Shapiro for frequent and useful help.

\section{References}

(1) D.W. Faufett and (.'J'. Fulton, Large Least Squares p'rublecus involving Kronecker J'rodncts, SIAM J. Mr trix Anal. Appl. 15 (1) (1994), 219-227.

[2] D.W. Fausett, C.T. Fulion and H. Hashish, Inproved Parallel QR Method for laarge J,casit Squares Problems invalving Kronecker Products, Technical Raporl, Jor partment of Applied Mathematies, liloridu Insilule of Technology, 1994.

[3] CMSSL for OMFortran, Vers. 3.2, "Ihinking Marlines Corporation, Cambridge, Mass., April 1999.

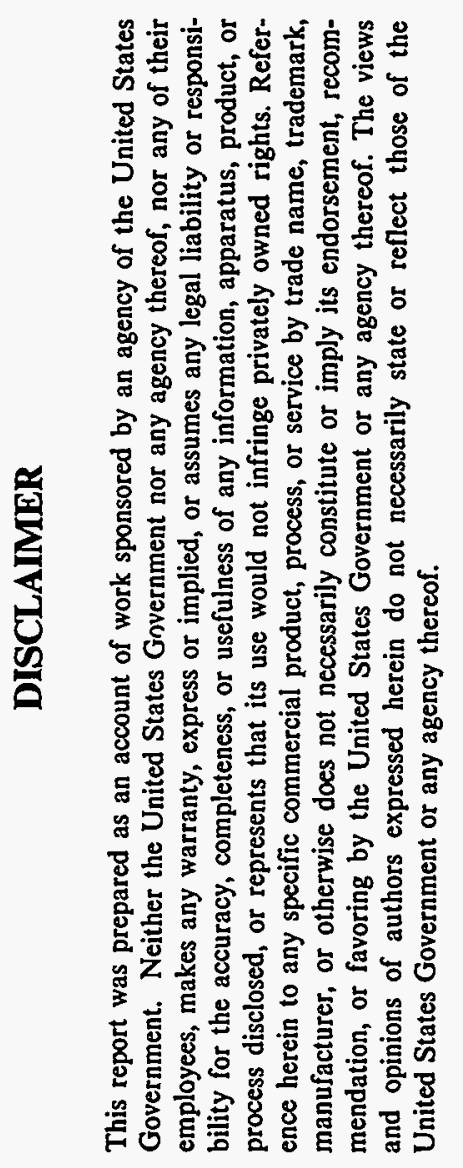

